\title{
Dynamics of tRNA fragments and their targets in aging
}

\section{mammalian brain [version 1; peer review: 2 approved]}

\author{
Spyros Karaiskos, Andrey Grigoriev
}

Department of Biology, Center for Computational and Integrative Biology, Rutgers University, Camden, USA

\author{
V1 First published: 24 Nov 2016, 5(ISCB Comm J):2758 \\ https://doi.org/10.12688/f1000research.10116.1 \\ Latest published: 24 Nov 2016, 5(ISCB Comm J):2758 \\ https://doi.org/10.12688/f1000research.10116.1
}

\section{Open Peer Review \\ Approval Status \\ 1 2 \\ version 1 \\ 24 Nov 2016

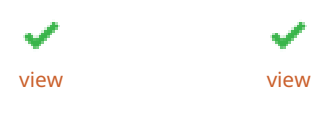 \\ 1. Tatiana V. Tatarinova, University of \\ Southern California, Los Angeles, USA \\ 2. Laura Kamenetzky, University of Buenos \\ Aires (UBA) and National Scientific and \\ Technical Research Council (CONICET), \\ Buenos Aires, Argentina \\ Natalia Macchiaroli, University of Buenos \\ Aires (UBA) and National Scientific and \\ Technical Research Council (CONICET), \\ Buenos Aires, Argentina \\ Any reports and responses or comments on the article can be found at the end of the article.}


This article is included in the Bioinformatics

gateway.

Corresponding author: Andrey Grigoriev (andrey.grigoriev@rutgers.edu)

Competing interests: No competing interests were disclosed.

Grant information: This work was in part supported by the National Science Foundation to AG [DBI-1458202].

The funders had no role in study design, data collection and analysis, decision to publish, or preparation of the manuscript.

Copyright: @ 2016 Karaiskos S and Grigoriev A. This is an open access article distributed under the terms of the Creative Commons Attribution License, which permits unrestricted use, distribution, and reproduction in any medium, provided the original work is properly cited.

How to cite this article: Karaiskos $\mathrm{S}$ and Grigoriev A. Dynamics of tRNA fragments and their targets in aging mammalian brain [version 1; peer review: 2 approved] F1000Research 2016, 5(ISCB Comm J):2758 https://doi.org/10.12688/f1000research.10116.1

First published: 24 Nov 2016, 5(ISCB Comm J):2758 https://doi.org/10.12688/f1000research.10116.1 


\section{Introduction}

Small RNA molecules derived from fragmented tRNAs form a new class of short ( 16-40 nt) RNA molecules. They arise from directed cleavage of cellular tRNAs, including both tRNA precursor species, as well as mature, functional tRNA molecules, and have been associated with multiple infectious diseases, pathogen resistance and regulation ${ }^{1,2}$. Early reports described such fragments resulting from cleavage of tRNAs in Escherichia coli as a protective response to phage infection and as "biochemical warfare" directed against unrelated bacterial strains ${ }^{3,4}$. Subsequent studies have expanded the known domain of these fragments to $\operatorname{archaea}^{5}$, eukaryotes ${ }^{6-8}$, including their parasites ${ }^{9,10}$, and to human cells $\mathrm{s}^{7,11-14}$. Broadly, the fragments are categorized into two types based on length and biogenesis: tRNA halves and tRNA-derived fragments (tRFs); this paper is focused on the latter. Studied and reviewed by several experimental groups ${ }^{15-18}$, tRFs are molecules of 16-24 nt in length and can be classified into three types based on the tRNA region from which they derive: 5' tRF, 3'CCA and 3' $U$ tRF. The last two types originate from the 3 ' end of the tRNA, while the first is derived from the 5' end. The 3'CCA type is generated from the 3' end of the mature tRNA and includes the CCA that is added to all tRNAs post-transcriptionally. The 3' $U$ type is derived from the uracil rich trailer sequence upstream of the 3 ' end of the precursor tRNA molecule and has multiple Us added to the 3 ' end. There have been various attempts to determine the biogenesis and function of these different types of tRNA-derived small RNAs, but currently most of these questions are still open.

Hypothesized to function similarly to microRNAs (miRNAs), either by regulating mRNAs (like miRNAs) or by affecting miRNA loading and processing ${ }^{7,11,19}$, tRFs have also been shown to bind to Argonaute complexes in multiple species ${ }^{20,21}$, strengthening their likely role in RISC-mediated gene silencing. A meta-analysis of PAR-CLIP libraries found that both 5' and 3' CCA tRFs were loaded to Ago1, Ago3, and Ago4, but 3' U tRFs did not associate with Argonaute proteins in great numbers in human cells ${ }^{21}$. A recent study suggested a traditional miRNA-like silencing based on complementarity of the 5' seed sequence of a tRF to a sub-sequence

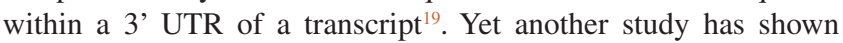
that the last $8-10 \mathrm{nts}$ on the 3' end of the tRF are responsible for mRNA repression ${ }^{22}$. In our lab, using a computational approach similar to detection of miRNA seeds, we have found potential seed regions on both a 5' -and a 3' tRF end ${ }^{23}$. Adding to this similarity, we have also reported age-related changes of tRF abundance in Drosophila melanogaster ${ }^{23}$, comparable to those detected for miRNA in the same organism ${ }^{20}$. Such changes with age were also detected in tRFs of Caenorhabditis elegans ${ }^{24}$.

Here, we report on further support for such miRNA likeness of tRFs in another experimental system, which shows that both of these types of small RNA may participate in the mechanisms of brain aging. Aging underlies cognitive decline and dementia, and is the greatest risk factor for the failure of brain functioning in adults. Analysis of aging brain can shed light on the basic neurological mechanisms and their connections with age-related neurodegenerative conditions, such as Alzheimer's and Parkinson's disease $^{25}$. Neurological research has used rats extensively over many years as models for mammalian behavioral and neurodegeneration studies. In the present study, we analyzed available RNA sequencing libraries produced from the brains of rats of different ages $^{26}$ and identified numerous tRFs, which showed consistent changes in their abundance patterns with age. We also confirmed in rat brains our previous findings on possible targeting mode of Drosophila tRFs and the functional enrichment of their targets in neuronal and developmental functions ${ }^{23}$. Potential targets of tRFs with clearly defined seeds showed higher levels of down-regulation with age compared to the rest of the brain transcriptome and to the targets of miRNAs upregulated with age. Our results strengthen the emerging consensus that tRFs are a novel class of non-coding RNA molecules; they target mRNAs in a manner similar to miRNAs and their abundance in the cell is dynamically regulated with regards to aging.

\section{Methods}

\section{Small RNA analysis}

We used small RNA sequencing libraries from brains of the rat Rattus norvegicus ${ }^{26}$ publicly available from the European Nucleotide Archive (accession number, ERA365111). Using the sra-toolkit 2.8.0 (https://trace.ncbi.nlm.nih.gov/Traces/sra/sra. cgi?view=software) we converted the sra files to fastq format. We used fastx toolkit 0.0.13 (http://hannonlab.cshl.edu/fastx_toolkit/) to clip the adapter sequences and collapse identical reads. The reads of length above $16 \mathrm{nts}$ were used for downstream analysis. We collapsed and mapped the reads to the rat genome (rn6, http:// hgdownload.soe.ucsc.edu/goldenPath/rn6/bigZips/), and also to the union of rat tRNAs from two independent databases (http://gtrnadb. ucsc.edu and http://trnadb.bioinf.uni-leipzig.de, also including mitochondrial tRNA genes from the latter) using Bowtie (version 1.1.1, released on 10/1/2014, http://bowtie-bio.sourceforge.net/ index.shtml). Bowtie parameters were set to output only perfect matches to tRNA sequences, including the post transcriptional CCA modification. Read counts in each experiment were normalized by the total number of reads detected, and averaged across three replicates for each of the three time points (ages of 6,14 and 22 months). For further analysis, we selected only tRFs with read counts $>0.1 \%$ of total reads in every replicate.

\section{Seed sequence analysis}

We generated 7-mer subsequences of tRFs by applying a 7-nt sliding window and shifting by one nt from the 5 ' to the 3 ' end. We then found the counts of exact matches for each of these subsequences to the 3' UTR regions conserved in at least 15 species (always including human, mouse and rat) out of 23 (Table 1; alignments obtained from http://www.targetscan.org/). To estimate significance of the seed matches, we compared the observed match counts for each respective 7-mer in a tRF to (i) the expected number of matches by chance (estimated from 7-mer genomic frequency) and (ii) the average number of matches of all possible 7-mers with the same nucleotide composition in conserved 3'UTRs. Genes with exact matches of 7-mer and 7-mer_1a candidate seeds to the 3'UTR were considered potential targets. 


\begin{abstract}
Table 1. Vertebrate species used for finding seed sequence matches. In total, 23 species are listed with their taxonomy IDs. Matches in at least 15 of these species were required, always including human, mouse and rat (shaded rows)
\end{abstract}

\begin{tabular}{|r|l|}
\hline Taxonomy ID & Species \\
\hline 10090 & Mus musculus \\
\hline 10116 & Rattus norvegicus \\
\hline 10141 & Cavia porcellus \\
\hline 13616 & Monodelphis domestica \\
\hline 28377 & Anolis carolinensis \\
\hline 30611 & Otolemur garnettii \\
\hline 37347 & Tupaia belangeri \\
\hline 42254 & Sorex araneus \\
\hline 9364 & Xenopus tropicalis \\
\hline 9258 & Gallus gallus \\
\hline 9361 & Ornithorhynchus anatinus \\
\hline 9365 & Erinaceus europaeus \\
\hline 9371 & Echinops telfairi \\
\hline 9544 & Macaca mulatta \\
\hline 9598 & Pan troglodytes \\
\hline 9606 & Homo sapiens \\
\hline 9615 & Canis lupus familiaris \\
\hline 9685 & Felis catus \\
\hline 9785 & Loxodonta africana \\
\hline 9796 & Equus caballus \\
\hline 9913 & Bos taurus \\
\hline 9986 & Oryctolagus cuniculus \\
\hline & \\
\hline & \\
\hline &
\end{tabular}

RNA sequencing analysis

For target expression analysis, we downloaded files with precomputed transcript expression levels for the rat cerebral cortex transcriptome (GEO data series; accession number, GSE34272 ${ }^{27}$ ). The expression levels in each experiment were normalized by the total number of reads detected and averaged across three replicates for each of the three time points (ages of 6,12 and 28 months).

\section{Statistical evaluation of downregulation levels for miRNA and tRF targets}

For each set of predicted targets of a tRF or miRNA, we compared its ratio of down-regulated/up-regulated target transcripts from young to old rats with the distribution of such ratios calculated for 1,000 randomly selected transcript sets (from the same transcriptome) of the same size as the target set (different for each $\mathrm{tRF}$ and miRNA). This process was repeated for three different thresholds (up-regulated by $>5 \%$ / downregulated by $>5 \%$; up-regulated by $>10 \%$ / downregulated by $>10 \%$; and up-regulated by $>20 \%$ / downregulated by $>20 \%$ ), and the statistical significance of the differences observed was obtained using two-tailed t-test in the R package (version 3.3.1; www.R-project.org).

\section{Gene ontology enrichment analysis}

The predicted targets for each tRF were used as input in order to perform GO enrichment analysis. Each set of targets was uploaded to PANTHER website (http://pantherdb.org/; version $11.1^{28}$ ) and results were obtained using the website default parameters.

\section{Results and discussion \\ tRNA fragments in rat brain}

We analyzed available datasets of nine different small-RNA libraries corresponding to three replicates for three distinct time points throughout a rat lifespan. These libraries were originally produced to study miRNA in the brains of young, middle-aged and old rats ${ }^{26}$. We will refer to the results associated with these three time points (6, 14 and 22 months) as $\mathrm{Y}, \mathrm{M}$ and $\mathrm{O}$, respectively. After mapping short RNA reads from these libraries to the union of tRNA sequences obtained from two independent databases (http:// gtrnadb.ucsc.edu; http://trna.bioinf.uni-leipzig.de), we observed that the vast majority of alignments localized preferentially to a 5 '- or a 3'-end of a tRNA molecule. Only 1-7\% of the reads among the nine sequencing experiments aligned elsewhere on the tRNA sequence. In the datasets we analyzed, a negligible number of reads aligned to 3' $\mathrm{U}$ tRFs, therefore we limited our focus to 5' and 3' tRFs, for which there was extensive evidence. The two dominant tRF classes appeared likely to be generated by different mechanisms of cleavage. For instance, there was a striking consistency regarding the cleavage site location in 3 ' $\mathrm{tRFs}$, compared to a wider distribution of those sites in 5' tRFs (Figure 2), supporting the notion that tRFs are not byproducts of random degradation, but have specific structure-dependent cleavage sites.

Age-related patterns of tRF abundance

We then analyzed age-related abundance of 3' and 5' tRFs in the brain. Interestingly, we observed a very common trend of an overall monotonous increase in the $3^{\prime}$ tRF levels with age, $\mathrm{Y}<\mathrm{M}<\mathrm{O}$ (Figure 3; Table 2). In striking contrast, the 5' tRFs displayed a much less consistent picture (Figure 4; Table 2), with several cases of monotonous increase or decrease with age, but mostly with a visibly different pattern of change $\mathrm{M}<\mathrm{Y}<\mathrm{O}$ (Figure 5). This difference, together with the cleavage site distributions (Figure 2), suggests that distinct processes are likely responsible for the generation of $3^{\prime}$ and $5^{\prime}$ tRFs, which may be relevant for their function.

\section{Computational prediction of tRF seeds and their targets}

Given the significant levels of tRFs in rat brains and their dynamic changes with age, we aimed to investigate their possible effect on the brain transcriptome. Although the mechanism of tRF action is yet to be elucidated, there is recent evidence suggesting an animal miRNA-like pathway of action. Previous reports have detected tRNA fragments in the cytoplasmic fraction of various human cells, including B-cells and A549 cells ${ }^{22,29}$, as well as mouse ES cells, plant cells, fission yeast cells and carcinoma cell lines, including HepG2, LNCap and LNCap-derived C4-2 $2^{13,30-33}$. It has been 


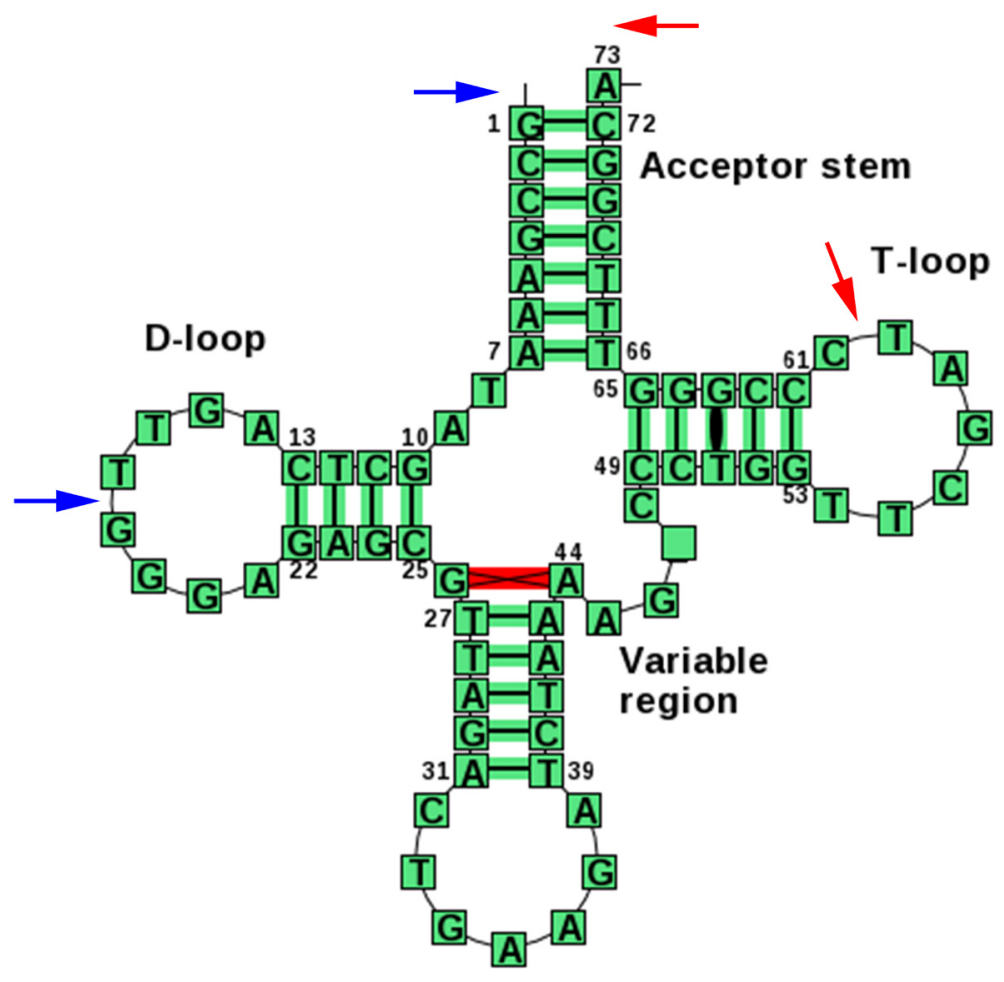

\section{Anticodon loop}

Figure 1. Typical endpoints of tRNA fragments. Typical secondary structure representation for the PheGAA tRNA gene (from http://trnadb. bioinf.uni-leipzig. de). Blue arrows point to typical endpoints for a 5' tRF. Red arrows indicate the ends of the most frequent 3' tRF. The mature tRNA molecule also contains the post-transcriptional 3' CCA modification (as does the 3' tRF). A 3' U tRF would derive from the uracil-rich trailer sequence downstream of the end of the tRNA gene (not shown).

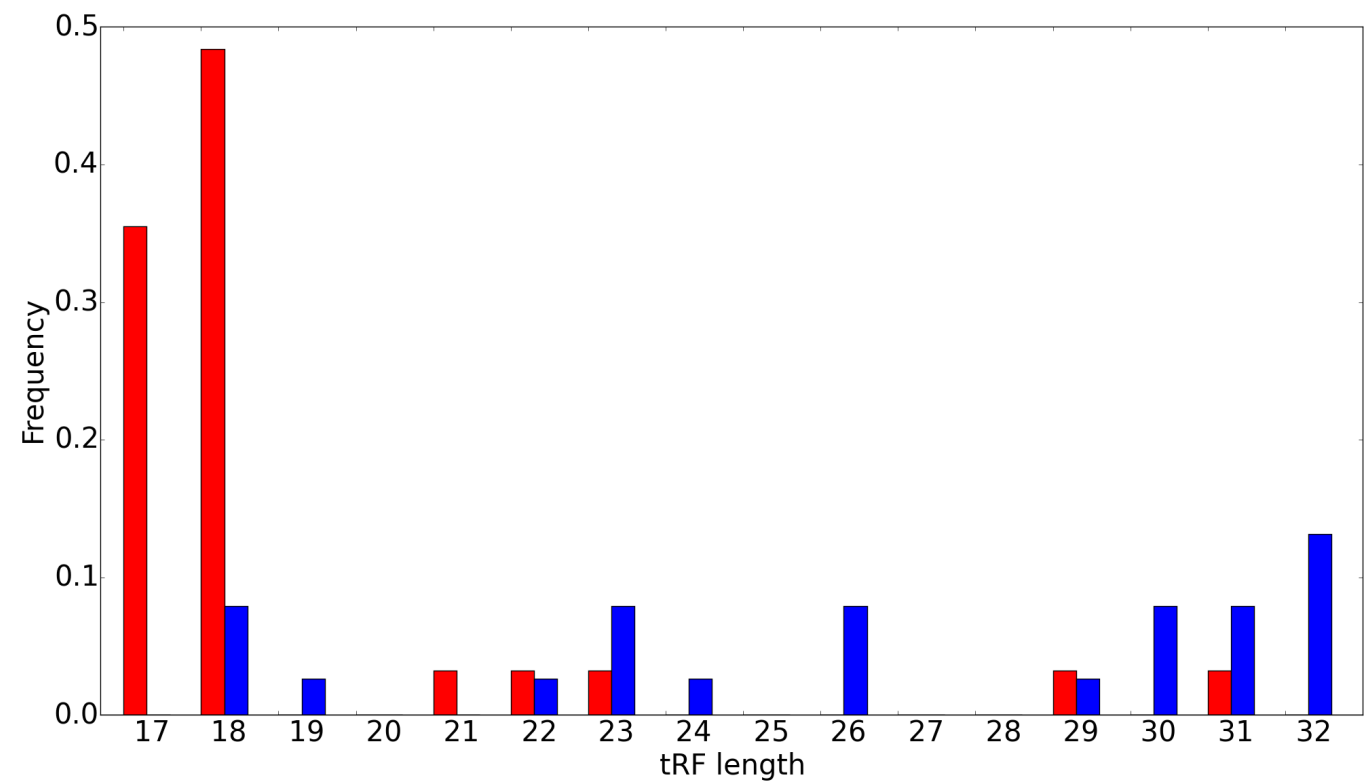

Figure 2. Differences in length distribution of tRFs. Length distributions for 5' (blue) and 3' (red) tRFs. tRF length is shown on the X-axis and the frequency on the y-axis. Note the much broader variability for the 5' tRFs. 


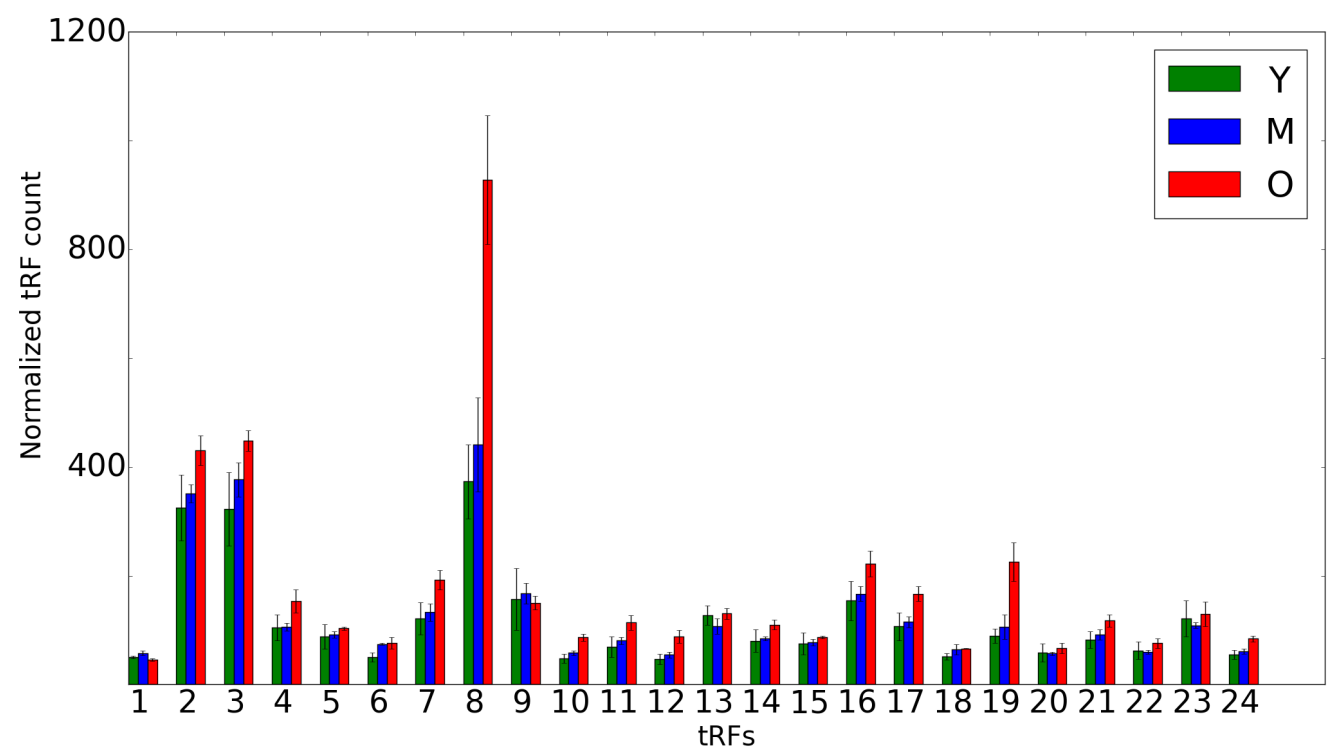

Figure 3. Age-related change in 3' tRF levels. Abundance of $3^{\prime}$ tRFs in rat brains for 3 distinct time points ( $Y$ is shown in green, $M$ in blue and $\mathrm{O}$ in red). An average of 3 replicates for each tRF is shown on the $\mathrm{X}$-axis for each time point. Error bars indicate the range of read counts. The $y$-axis shows the normalized tRF abundance; the numbers on the x-axis correspond to tRNA genes listed in Table 2. Y, young (6 months); M, mid-age (14 months); O, old (22 months).

Table 2. tRFs shown in Figure 3 and Figure 4. The tRNA anticodon is shown in column 1, the tRNA ID in column 2 and the corresponding numbers used as an $x$ axis label for Figure 3 and Figure 4 (when applicable) are shown in columns 3 and 4, respectively. A database, which each matching tRNA gene was downloaded from, is shown in column 5: *http://gtrnadb.ucsc.edu; **http://trnadb. bioinf.uni-leipzig. de. Additionally, a dollar sign (\$) in column 5 , indicates that a potential seed was detected in this tRF. Coordinates of tRFs on the matching tRNA genes are given in column 6.

\begin{tabular}{|l|l|r|l|l|l|}
\hline $\begin{array}{l}\text { tRNA } \\
\text { Anticodon }\end{array}$ & tRNA ID & $\begin{array}{l}\text { Figure } 3 \\
\text { (3' tRFs) }\end{array}$ & $\begin{array}{l}\text { Figure } \\
\text { (5' tRFs) }\end{array}$ & Database & $\begin{array}{l}\text { tRF Coordinates on } \\
\text { tRNA molecule (3', }\end{array}$ \\
\hline when both are shown)
\end{tabular}




\begin{tabular}{|c|c|c|c|c|c|}
\hline $\begin{array}{l}\text { tRNA } \\
\text { Anticodon }\end{array}$ & tRNA ID & $\begin{array}{l}\text { Figure } 3 \\
\text { (3' tRFs) }\end{array}$ & $\begin{array}{l}\text { Figure } 4 \\
\text { (5' tRFs) }\end{array}$ & Database & $\begin{array}{l}\text { tRF Coordinates on } \\
\text { tRNA molecule }\left(3^{\prime}, 5\right. \\
\text { when both are shown) }\end{array}$ \\
\hline AlaTGC & trna5057 & 18 & 14 & ${ }^{*}, \$$ & $58-75,1-22$ \\
\hline ProAGG & trna13311 & 19 & -- & * & $58-75$ \\
\hline GlyGCC & trna1527 & 20 & 5 & * & $58-74,1-30$ \\
\hline ArgACG & $\operatorname{trna1600}$ & 21 & -- & * & $60-76$ \\
\hline GlyTCC & trna2250 & 22 & -- & * & $59-75$ \\
\hline GlyCCC & trna7585 & 23 & -- & * & $57-74$ \\
\hline GlyCCC & trna2752 & 24 & -- & * & $57-74$ \\
\hline IniCAT & MtdbD00003481 & -- & 1 & ** (mitochondrial) & $1-30$ \\
\hline GlyGCC & trna2377 & -- & 2 & * & $1-18$ \\
\hline GlyGCC & trna2376 & -- & 3 & * & $1-32$ \\
\hline GlyGCC & trna3490 & -- & 4 & * & $1-18$ \\
\hline GlyGCC & trna1897 & -- & 6 & * & $1-31$ \\
\hline GlyGCC & trna1528 & -- & 7 & * & $1-32$ \\
\hline GlyGCC & trna11254 & -- & 8 & * & $1-34$ \\
\hline LysCTT & trna7564 & -- & 9 & * & $1-26$ \\
\hline LysCTT & trna2975 & -- & 10 & * & $1-33$ \\
\hline LysCTT & trna13312 & -- & 11 & * & $1-34$ \\
\hline HisGTG & trna3497 & -- & 12 & * & $1-30$ \\
\hline HisGTG & trna4377 & -- & 13 & * & $1-33$ \\
\hline AlaTGC & trna12492 & -- & 15 & * & $1-23$ \\
\hline CysGCA & trna8932 & -- & 16 & * & $1-32$ \\
\hline CysGCA & trna8966 & -- & 17 & * & $1-33$ \\
\hline TyrGTA & MtdbD00003620 & -- & 18 & ** (mitochondrial) & $1-31$ \\
\hline SerAGA & trna3680 & -- & 19 & * & $1-23$ \\
\hline LeuCAG & trna2365 & -- & 21 & $*, \$$ & $1-18$ \\
\hline LeuCAG & trna2370 & -- & 22 & * & $1-26$ \\
\hline ValCAC & trna1607 & -- & 23 & * & $1-23$ \\
\hline ValAAC & trna3670 & -- & 24 & * & $1-33$ \\
\hline ValCAC & trna1601 & -- & 26 & * & $1-33$ \\
\hline ValCAC & trna4363 & -- & 27 & * & $1-36$ \\
\hline GInTTG & trna4 & -- & 28 & * & $1-36$ \\
\hline GluCTC & tdbD00000658 & -- & 29 & $* *, \$$ & $1-19$ \\
\hline GluCTC & trna2251 & -- & 30 & * & $1-34$ \\
\hline
\end{tabular}

proposed that $\mathrm{tRF}$ are likely to function similarly to a traditional miRNA-like mode, using perfect complementarity of the 5' seed sequence of the tRF (typically, positions $2-8$ in miRNAs) to target a subsequence within a 3' UTR of a transcript ${ }^{29}$. Contrary to the above, an alternative mode of action for tRFs has been suggested by a study ${ }^{22}$, which utilized luciferase reporter assays to demonstrate that a potential seed sequence resided in the 3' end of the tRNA fragment, ruling out a 5' and a middle segment seed binding.
A search for a near-perfect complementarity of tRF sequences against transcripts yielded very few results, both in the 12 Drosophila genomes ${ }^{23}$ and in the present study, further suggesting a targeting mode similar to animal miRNAs. Assuming such an animal-like miRNA targeting mechanism for tRFs, we further investigated the targeting mechanism of tRFs and adjusted our computational pipeline, used previously to find targets in 12 Drosophila genomes ${ }^{23}$, to perform the tRF seed search in 


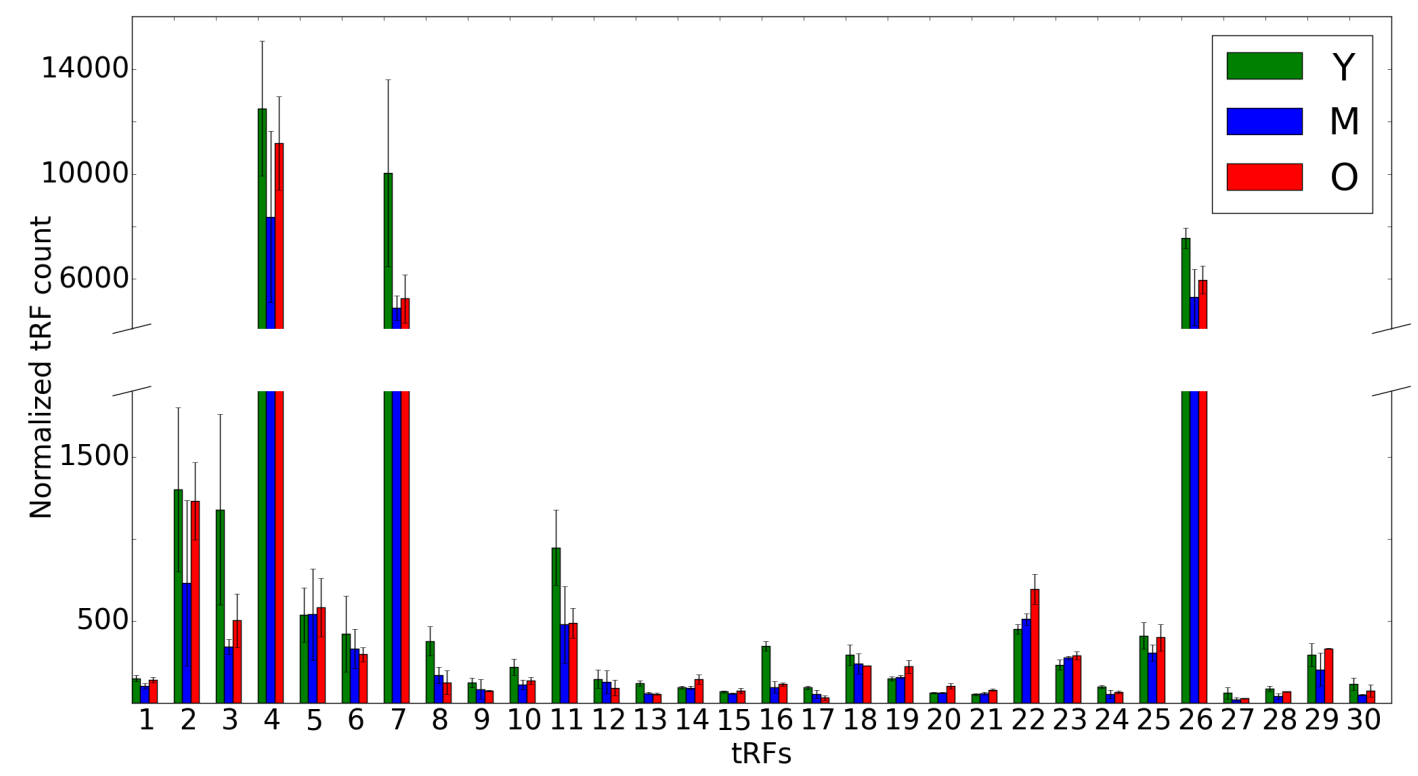

Figure 4. Age-related change in 5' tRF levels. Abundance of $5^{\prime}$ tRFs in rat brains for 3 distinct time points ( $Y$ is shown in green, $M$ in blue and $O$ in red). An average of 3 replicates for each tRF is shown on the $x$-axis for each time point. Error bars indicate the range of read counts. The $y$-axis shows the normalized tRF abundance; the numbers on the $x$ axis correspond to tRNA genes listed in Table 2. Y, young (6 months); $\mathrm{M}$, mid-age (14 months); O, old (22 months).

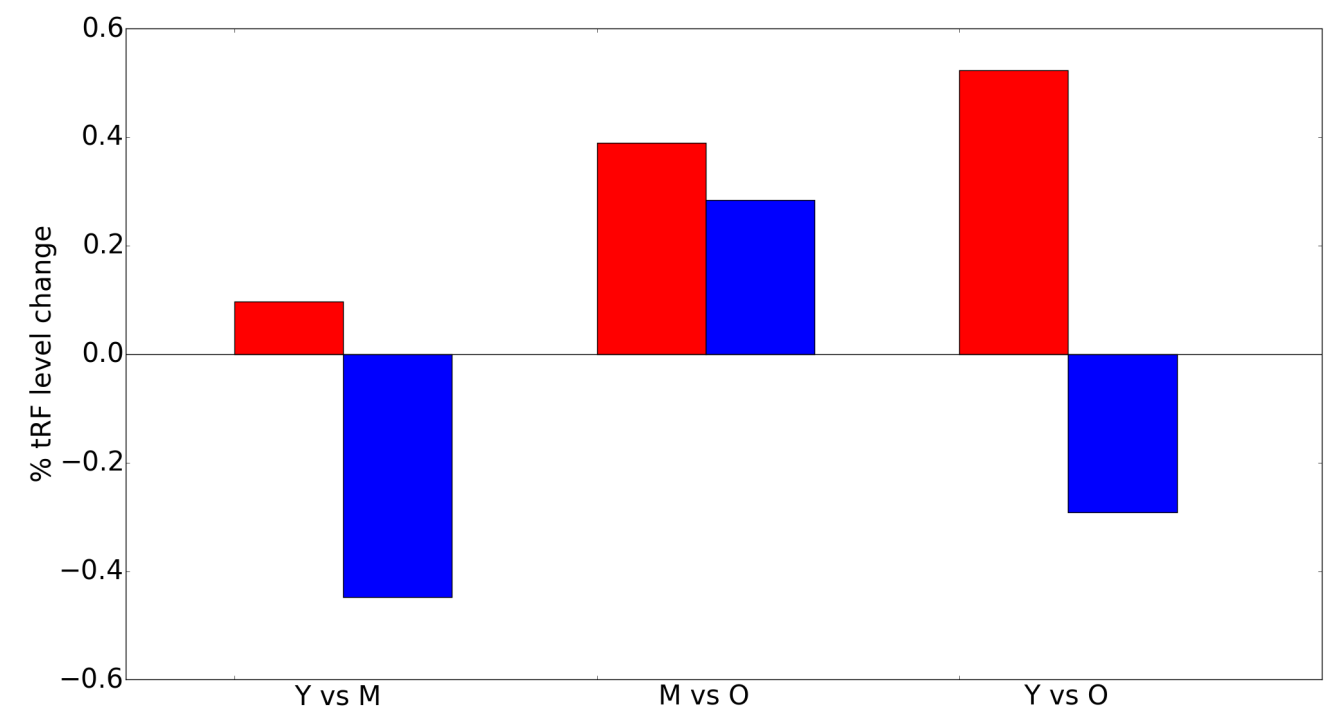

Figure 5. Total tRF abundance. Change in total abundance levels with age for all 5' tRFs (blue) and 3' tRFs (red). Y, young (6 months); M, mid-age (14 months); O, old (22 months).

mammalian genomes. This pipeline functions similarly to the approach used to identify such seed sequences for miRNAs ${ }^{34}$. We used 7-nt sliding windows across the length of a tRF sequence and aligned them against conserved 3' UTR regions of 23 vertebrate species. The region was considered conserved if it was found in 15 genomes (always including rat, mouse and human) out of these 23
(Table 1). We took into consideration the following match types: 7-mer-m8 (full 7-mer match), 7-mer-1a (perfect match of the first $6 \mathrm{nts}$ followed by an A in the 3' end of the targeted transcript) and 8-mer-1a (perfect 7-mer match followed by an A in the 3' end), which have been extensively confirmed for miRNAs in the past ${ }^{35}$. Our results in finding seeds (Table 2) demonstrate that such 
conserved matches can be located both on the $5^{\prime}$ end and on the 3 ' end of the tRF (Figure 6), concordant with the existing experimentally validated results for tRF targeting mechanisms ${ }^{22,29}$. A similar arrangement of the seed regions on the 5' end and on the 3' end of the tRF has also been observed in Drosophila ${ }^{23}$.

The success in finding seeds (Table 2) was overwhelmingly in favor of shorter 3' tRFs (6 out of $24,25 \%$ ) compared to longer 5 ' tRFs (2 out of $30,6.67 \%$ ). Given the number of differences between these two tRF types, we chose to focus on 3' tRFs for the remainder of this paper. For our meta-analysis, detailed in the sections below, we combined experimental results performed in different labs, with different brain material, and at different ages (e.g., 22 months in small RNA-seq series is quite far from both 12 and 28 months in RNA-seq series). Given the small changes in gene expression and to avoid the effects of nonmonotonous changes in many 5 'tRFs, we limited our subsequent analysis to six 3' tRFs (Figure 6), which showed monotonous changes in their levels from $\mathrm{Y}$ to $\mathrm{M}$ to $\mathrm{O}$ and clearly defined seed sequences.

\section{Gene ontology enrichment analysis of conserved predicted} targets

Following our seed region identification for tRFs, we focused on their predicted targets with conserved seed matches within their 3' UTR (Supplementary File 1). We explored potential functions of targets of six tRFs that showed clearly defined seed sequences (Figure 6). Gene Ontology (GO) enrichment analysis of conserved predicted targets of these tRFs revealed $>150$ significantly enriched GO terms for biological process. "Nervous system development" was found to be consistently enriched for all six tRFs, except ProTGG. Additional biological process GO terms, such as "central nervous system development", "neurogenesis" and "axonogenesis", were also enriched for multiple tRF targets (Supplementary File 2). Furthermore, the same tRF targets that showed an enrichment for nervous system functionality and development were also associated with significantly enriched neuron/axon-related cellular localization terms (Supplementary File 2). Overall, these results are in agreement with our previous work on D. melanogaster ${ }^{23}$, where we have noted a similar enrichment for biological processes related to neuronal function and development for predicted targets of tRFs increasing with age from young to adult flies. However, in addition to these functions, ProTGG and other tRFs also appeared to target transcription and splicing regulators in rat brains (Supplementary File 1 and Supplementary File 2).

\section{Expression patterns of predicted tRF targets}

We compared our observations of tRF abundance changes with age to the measured expression levels of their targets. We compared the profiles of all mRNAs in the rat cerebral cortex transcriptome ${ }^{27}$ with those predicted to be targeted by miRNAs (using Targetscan ${ }^{34}$ ) and by tRFs (using perfect matching of the identified tRF seed sequence and a conserved target sequence located in the 3' UTR of a transcript). We calculated the ratios of down- to up-regulated transcripts for the whole rat cortex transcriptome and for the targets of six 3' tRFs (in which seeds could be clearly seen, Figure 6) and five miRNAs (Table 3 ) that had $>500$ raw reads in the old age, and, similarly to 3 ' tRFs, showed a monotonous increase $\mathrm{Y}<\mathrm{M}<\mathrm{O}$. We observed that both tRF and miRNA targets were significantly enriched for down-regulated transcripts at three different regulation thresholds (Table 3). Interestingly, the enrichment for down-regulation in the union set of all neuron-related tRF targets was also significant $(\mathrm{p}<0.05)$ for each of these three thresholds of regulation.

Comparing the distributions of de-regulation levels from young to old age for (i) all mRNAs detected in rat cortex, (ii) for miRNAtargeted mRNAs and (iii) for tRF targets (Figure 7), we observed a consistently higher proportion of down-regulated and lower proportion of up-regulated targets in both miRNA and tRF groups of targets compared to all mRNAs. Although these proportions for
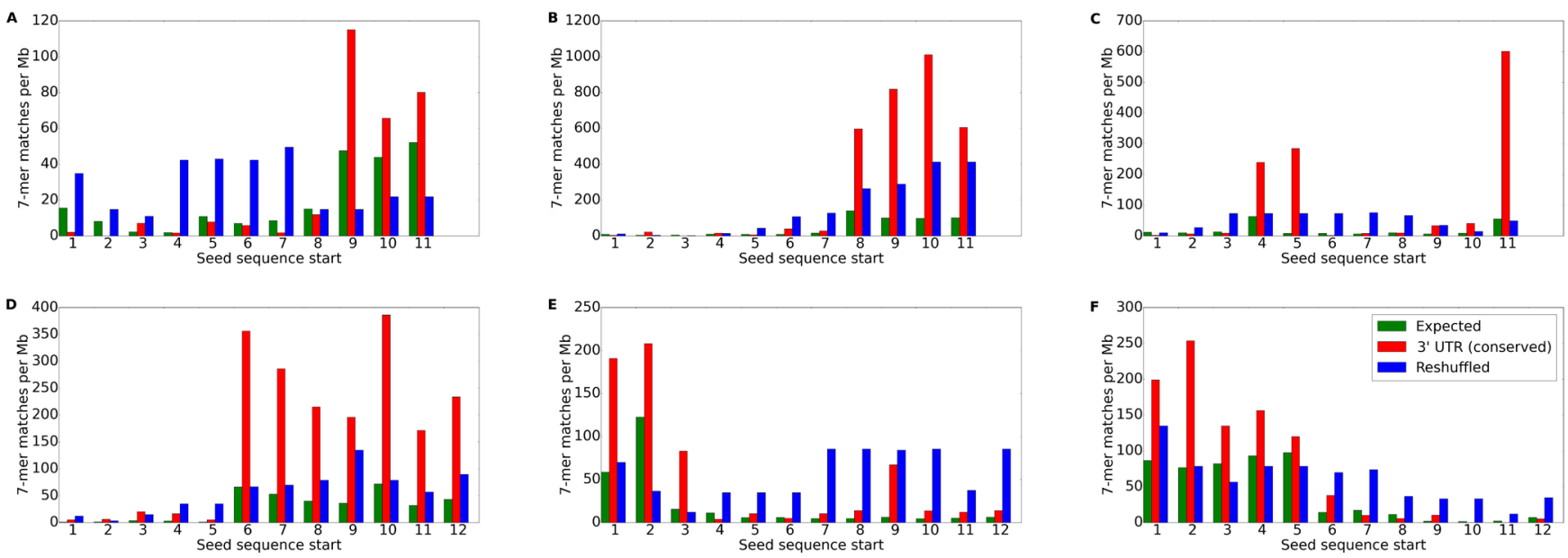

Figure 6. Candidate seed region locations for tRFs. The numbers of exact sequence matches in the 3' UTR regions are plotted against the starting position of a 7-mer. Expected number of matches in 3' UTRs is shown in yellow, average number of conserved matches for all other 7-mers with the same nucleotide composition as the given window is shown in blue, and the observed number of matches in the conserved regions of 23 vertebrates is shown in red. The letters on the top left corners of each plot correspond to individual tRFs: (A) ProTGG, (B) ValAAC, (C) PheGAA, (D) AlaTGC, (E) SerAGA and (F) SerGCT. 
Table 3. Age-related down-regulation of tRF/miRNA

targets. Ratios of down-regulated/up-regulated miRNAand tRF-targeted transcripts for each of the change thresholds ( $>5 \%,>10 \%,>20 \%$ ). Significant difference from the expected ratio is indicated by ${ }^{* *} \mathrm{p}<0.005$ ${ }^{* *} p<0.01 ;{ }^{*} p<0.05 ; \# p>0.05$.

\begin{tabular}{|c|c|c|c|}
\hline tRF & Ratio (>5\%) & Ratio (>10\%) & Ratio (>20\%) \\
\hline ProTGG & 11.0 *** & $7.0 * \star \star$ & 4.0 ** \\
\hline AlaTGC & 2.15 * & 2.57 ** & 0.5 * \\
\hline PheGAA & $3.33^{* \star \star}$ & $3.7^{* \star \star}$ & $3.25^{* \star *}$ \\
\hline SerAGA & $4.0 * * *$ & $4.0 * * *$ & 3.0 * \\
\hline SerGCT & $4.0 * * *$ & $3.5^{* \star *}$ & 2 * \\
\hline ValAAC & $4.1^{* \star *}$ & $3.5^{\star \star \star}$ & $1.5 \#$ \\
\hline miRNA & Ratio (>5\%) & Ratio (>10\%) & Ratio (>20\%) \\
\hline mir-146b & $2.85^{\star * \star}$ & $2.46^{* *}$ & $4.25^{\text {***}}$ \\
\hline mir-132 & $2.31^{\star \star \star}$ & $2.24^{\star *}$ & $1.56^{\star}$ \\
\hline mir-128-2 & 2.52 *** & $2.3^{* \star \star}$ & $2.5^{\star \star *}$ \\
\hline mir-92a & $2.63^{\star * \star}$ & $2.43^{* * *}$ & 1.89 ** \\
\hline mir-200c & $2.71 * * \star$ & 2.96 *** & 1.96 *** \\
\hline
\end{tabular}

mRNAs and tRF targets were generally comparable, we noted a bimodal distribution for tRF targets, whereas such bimodality was much less pronounced for miRNA targets (Figure 7). Targets for both types of small RNAs show their most prominent peaks for low levels of down-regulation with age (these range from 0 to $-5 \%$ and are possibly related to targeting relevant in other cellular contexts or false positives in target predictions). However, the proportion of $\mathrm{tRF}$ targets down-regulated in the range of 10.0-22.5\%, and thus more likely to be relevant in the brain, is consistently higher compared to that of miRNA targets. Such (relatively low) level of change is not surprising, given that miRNAs are considered to be finetuning the transcriptional control by post-transcriptionally modulating the target transcript levels ${ }^{36}$. The age-related decrease in the mRNA levels for tRF targets is generally more pronounced than that for miRNA targets.

\section{Finding missed tRNA genes}

In our effort to identify every possible tRF present in rat brains, we took into account a union of all annotated rat tRNAs from two databases (http://gtrnadb.ucsc.edu; http://trnadb.bioinf.uni-leipzig. de). Although the latter database is rather small compared to the former, we found that it contained a handful of rat tRNA genes (to which tRF fragments did map perfectly), which were missing from the UCSC database at the time of our first analysis. Upon subsequent checking, we found that most of the missing tRNA genes

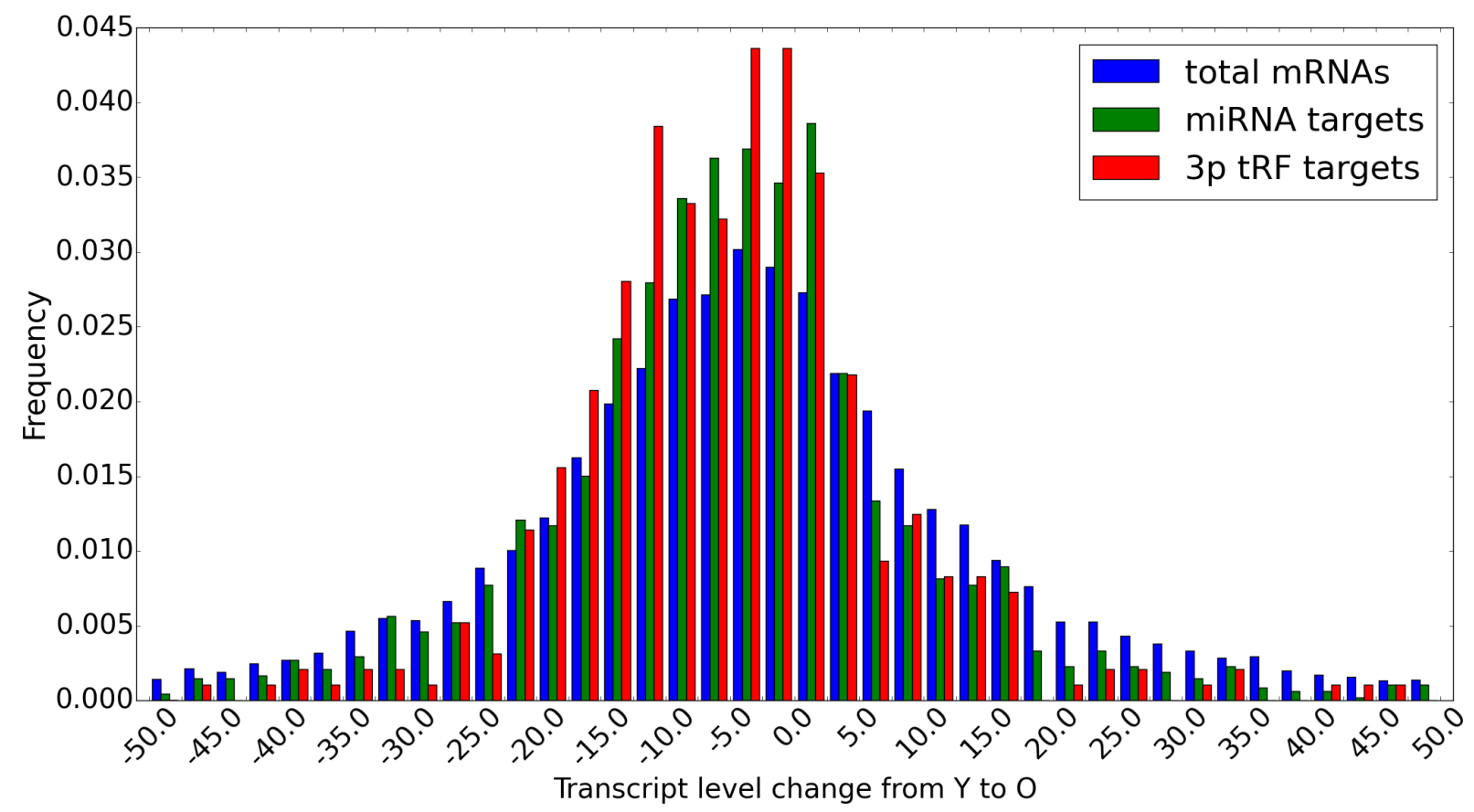

Figure 7. Changes in target transcript levels with age. Transcript level changes from young to old rat brains. Distributions of changes for all detectable mRNAs in rat brains (blue), miRNA-targeted (green) and 3' tRF-targeted transcripts (red) are shown using $2.5 \%$ bins. 
have been added correctly to the most recent update of the UCSC database (not including mitochondrial tRNAs). However, there is a tRNA gene (tdbD00000658-GluCTC; Table 2), which aligns perfectly to the rat genome (chr17:45,642,771-45,642,843 of rn6), and which is still absent in the latest version of the UCSC database. In our analysis, we detected tRFs from all nine sequencing libraries mapping to tdbD00000658-GluCTC sequence. Together with the fact that annotating tRNAs is not a typical priority in genome sequencing projects, our observations suggest that there are potentially other tRNA genes lacking annotation in the published genomes. However, such genes appear to be sources of detectable tRFs. Hence, analysis of tRFs can have an added value of revealing unannotated tRNA genes for multiple species.

\section{Discussion}

In this study we characterized tRFs present in rat brains at three different time points, revealing that their abundance is dynamically regulated in the context of age. Previously, we have reported agerelated changes in $D$. melanogaster $\mathrm{tRFs}^{23}$. While only two time points have been considered in that paper, it has shown the changes related to the tRF loading to Argonaute proteins and thus very likely related to the function of the RISC complex. Here we observed two typical patterns of change in tRF levels. One was a monotonous increase with age, primarily seen in 3' tRFs. Another was a lower abundance in mid-aged rat brains and higher abundance in young and old animals, mostly observed in 5' tRFs. These patterns, together with the differences in fragment sizes, suggest distinct mechanisms of cleavage for the two types of fragments, which can potentially be attributed to the different roles for these two types of tRFs. In addition to the biogenesis pathways, tRFs originating from different ends of the tRNA molecule have also been shown to localize in different sub-cellular compartments. As pointed out by Kumar et al. ${ }^{21}, 5$ ' tRFs were equally abundant in the nuclei and whole cell fraction of HeLa cell line ${ }^{37}$, indicating primarily nuclear localization, which is consistent with large numbers of 5 ' tRFs in HeLa cell nucleoli ${ }^{11}$. On the contrary, 3' tRFs showed an enrichment in the whole cell fraction, indicating their cytoplasmic localization (in agreement with Haussecker et al. ${ }^{12}$ ). There has been evidence of miRNAs actively loaded to Argonaute proteins in an age-dependent manner in D. melanogaster ${ }^{20}$. A very similar age-related loading pattern was also observed for $D$. melanogaster $\mathrm{RRFs}^{23}$. This, along with extensive evidence that Argonaute proteins are not only acting in post-transcriptional silencing but are localized/imported to the nucleus, could imply additional unknown functions for tRFs within the nuclear compartments of the cell. Perhaps such functions are similar to those previously described for miRNAs, which have been shown to be associated with mRNA splicing and modulation of histone epigenetic modifications ${ }^{38,39}$. This is a focus of our ongoing research.

Although the mode of action for tRFs is yet to be elucidated, our results support the hypothesis that mammalian tRFs (at least, 3' tRFs) can act in a very similar way to miRNAs in posttranscriptional gene silencing. We show here that they contain 7-mers, which match 3' UTR regions of transcripts at much higher rates than expected by chance, similar to the seed sequences of miRNAs. Searching for conserved matches across vertebrate genomes, we found such seeds on either end of the tRF molecules, as has been the case with 12 Drosophila species ${ }^{23}$. Previous studies have also detected both 5' and 3' seeds in different tRFs and changes in the seed sequence have been shown to affect the suppression of mRNA translation ${ }^{22,29}$. It is worth noting that in miRNAs, 3'-compensatory $\operatorname{sites}^{40}$ and central pairing sites ${ }^{41}$ have been reported in addition to the most prevalent $5^{\prime}$ seeds $^{34,35}$; thus, finding seeds on both ends of tRFs is not unexpected. Nontraditional seed region location in miRNA is also consistent with the extensive results of Helwak et $a l^{42}$, who reported that more than half of the observed miRNA-mRNA interactions do not show traditional seed binding properties in HEK-293 cells. However, one cannot exclude other modes of action, for example, ribosome targeting 5 . Additionally, tRFs have been reported to bind to oncogenic RNA-binding protein YBX1, displacing pro-oncogenic transcripts and acting as tumor suppressors ${ }^{43}$.

Interestingly, for tRFs with clearly defined seed-like regions, we observed a significant and consistent enrichment for targeted genes, whose Gene Ontology terms were related to neuronal function and development. Again, this was in agreement with a functional enrichment seen in Drosophila tRF targets ${ }^{23}$. However, in addition to these functions, rat brain tRFs also appeared to target transcription and splicing regulators, in parallel to earlier findings for rat brain miRNAs ${ }^{36}$. Some of the genes were predicted to be targeted by more than one tRF (Supplementary File 1), including well-known regulators of growth, such as PTEN or MAP3K1 (both targeted by three tRFs). These genes were seen down-regulated with age in the present study, consistent with their involvement in the developing nervous system. The highest number of tRFs (four) targeted the QK gene, whose human homolog has been implicated in oligodendrocyte-related gene expression abnormalities in schizophrenia ${ }^{44}$.

Having identified potential targets of 3' tRFs, we compared age-related changes in their transcript levels with the targets of upregulated miRNAs and observed small but significant downregulation of such targets for both groups of small RNAs. However, tRFs appeared to have more of their targets down-regulated to a greater extent with age compared to those of miRNAs. Among such down-regulated tRF targets with a well-defined role in the nervous system, a netrin receptor, UNC5C, is related to axon guidance and neural development. A mutation in this gene has been associated with predisposition to Alzheimer's disease and has been shown to cause increased neuronal cell death in rodents ${ }^{45}$. Cadherin genes, which are related to development and maintenance of functional structures in the central nervous system (reviewed in 46) were found in the present study to be targeted by tRFs (PCDH9). Fibroblast growth factor receptor-2 gene (FGFR2) was also found among the targets, suggesting that tRFs may affect key proteins involved in neural development, given that fibroblast growth factors are potent modulators of proliferation in the developing nervous system ${ }^{47}$.

As is the case with miRNAs, different tRFs appeared to affect down-regulation of their targets to a different extent with age (Table 3). The RISC pathway functions by repressing translation and by mRNA cleavage, and the exact balance of those mechanisms is not known. It has been speculated that degradation of repressed mRNAs by other mechanisms may be responsible for 
the observed decrease in their counts ${ }^{48}$. It is also unclear if the miRNA and tRF levels determined by RNA-seq correlate with their actual functional levels in the RISC complexes, or if the tRF entry into the RISC system in mammals is guarded, as seen in the yeast Schizosaccharomyces pombe $e^{31}$. Nevertheless, tRF targets appear to be more efficiently down-regulated compared to miRNA targets in aging rat brains (Figure 7). These present findings await experimental validation and may be of relevance for human aging and neurodegeneration studies, given the comparable gross structure of the rat and human brains and the role of rat models in neurological research.

\section{Data availability}

We have provided an archive with the data that should allow others to reproduce our results and figures presented in this paper. This archive is available via the Open Science Framework at https://osf. io/hz8en/, DOI: 10.17605/OSF.IO/HZ8EN ${ }^{49}$.

It contains output .txt files produced in the course of this study, including the following: (1) A description of output files (readme.txt); (2) $9 *$.tRNAs files, generated using Bowtie, which include all possible reads that mapped to tRNA genes; (3) 54 *.txt files, which are the output from the seed sequence identification pipeline.

The file format for the seed sequence identification pipeline output is as follows:

Column 1) Gene name

Column 2) 7-mer location on the tRF molecule

Column 3) Multiple Sequence alignment starting position

Column 4) Multiple Sequence alignment ending position

Column 5) 3' UTR starting position
Column 6) 3' UTR ending position

Column 7) Match type

Column 8) Species with this site type (Taxonomy ID, see Table 1)

Additional data are available from public repositories as follows: small RNA sequencing libraries, European Nucleotide Archive (accession number, ERA365111); transcript levels in the cortex transcriptome, GEO data series (accession number, GSE34272); miRNA targets, Targetscan (http://www.targetscan.org/cgi-bin/targetscan/data_download.cgi?db=mmu_71).

Author contributions

SK participated in the design of the study, analyzed the data, and drafted the manuscript. AG conceived the study, oversaw its design, execution and coordination, and drafted and finalized the manuscript. All authors were involved in the revision of the draft manuscript and have agreed to the final content.

\section{Competing interests}

No competing interests were disclosed.

Grant information

This work was in part supported by the National Science Foundation to AG [DBI-1458202].

The funders had no role in study design, data collection and analysis, decision to publish, or preparation of the manuscript.

Acknowledgments

We would like to thank Merve Ozbas for excellent technical help, and Sean Smith and Joseph Kawash for critical reading of an earlier version of the manuscript.

\section{Supplementary material}

Supplementary File 1. List of predicted conserved tRF targets for the six tRFs shown in Figure 6.

Click here to access the data.

Supplementary File 2. Gene Ontology enrichment analysis for the six tRFs shown in Figure 6.

Click here to access the data.

1. Garcia-Silva MR, Cabrera-Cabrera F, Güida MC, et al.: Hints of tRNA-Derived Small RNAs Role in RNA Silencing Mechanisms. Genes (Basel). 2012; 3(4): 603-14.

PubMed Abstract | Publisher Full Text | Free Full Text

2. Garcia-Silva MR, Cabrera-Cabrera F, Güida MC, et al:: Novel aspects of tRNA derived small RNAs with potential impact in infectious diseases. Adv BiosCi Biotechnol. 2013; 4: 17-25.

Publisher Full Text
3. Levitz R, Chapman D, Amitsur M, et al:: The optional E. coli prr locus encodes a latent form of phage T4-induced anticodon nuclease. EMBO J. 1990; 9(5): 1383-1389.

PubMed Abstract | Free Full Text

4. Ogawa T, Tomita K, Ueda T, et al:: A cytotoxic ribonuclease targeting specific transfer RNA anticodons. Science. 1999; 283(5410): 2097-100. PubMed Abstract | Publisher Full Text

5. Gebetsberger J, Zywicki M, Künzi A, et al.: tRNA-derived fragments target the 
ribosome and function as regulatory non-coding RNA in Haloferax volcanii. Archaea. 2012; 2012; 260909.

PubMed Abstract | Publisher Full Text | Free Full Text

6. Gong B, Lee YS, Lee I, et al:: Compartmentalized, functional role of angiogenin during spotted fever group rickettsia-induced endothelial barrier dysfunction: evidence of possible mediation by host tRNA-derived small noncoding RNAs. BMC Infect Dis. 2013; 13: 285.

PubMed Abstract | Publisher Full Text | Free Full Text

7. Li Z, Ender C, Meister G, et al.: Extensive terminal and asymmetric processing of small RNAs from rRNAs, snoRNAs, snRNAs, and tRNAs. Nucleic Acids Res. 2012; 40(14): 6787-99.

PubMed Abstract | Publisher Full Text | Free Full Text

8. Wei C, Salichos L, Wittgrove $\mathrm{CM}$, et al:: Transcriptome-wide analysis of small RNA expression in early zebrafish development. RNA. 2012; 18(5): 915-29. PubMed Abstract | Publisher Full Text | Free Full Text

9. Li Y, Luo J, Zhou H, et al:: Stress-induced tRNA-derived RNAs: a novel class of small RNAs in the primitive eukaryote Giardia lamblia. Nucleic Acids Res. 2008 36(19): 6048-55.

PubMed Abstract | Publisher Full Text | Free Full Text

10. Macchiaroli $\mathrm{N}$, Cucher M, Zarowiecki M, et al:: microRNA profiling in the zoonotic parasite Echinococcus canadensis using a high-throughput approach. Parasit Vectors. 2015; 8(1): 83

PubMed Abstract | Publisher Full Text | Free Full Text

11. Cole C, Sobala A, Lu C, et al:: Filtering of deep sequencing data reveals the existence of abundant Dicer-dependent small RNAs derived from tRNAs. RNA. 2009; 15(12): 2147-60.

PubMed Abstract | Publisher Full Text | Free Full Text

12. Haussecker D, Huang $Y$, Lau A, et al.: Human tRNA-derived small RNAs in the global regulation of RNA silencing. RNA. 2010; 16(4): 673-95. PubMed Abstract | Publisher Full Text | Free Full Text

13. Lee YS, Shibata $Y$, Malhotra A, et al.: A novel class of small RNAs: tRNA-derived RNA fragments (tRFs). Genes Dev. 2009; 23(22): 2639-49. PubMed Abstract | Publisher Full Text | Free Full Text

14. Yeung ML, Bennasser $\mathrm{Y}$, Watashi $\mathrm{K}$, et al:: Pyrosequencing of small non-coding RNAs in HIV-1 infected cells: evidence for the processing of a viral-cellula double-stranded RNA hybrid. Nucleic Acids Res. 2009; 37(19): 6575-86. PubMed Abstract | Publisher Full Text | Free Full Text

15. Anderson $P$, Ivanov $P$ : tRNA fragments in human health and disease. FEBS Lett 2014; 588(23): 4297-4304.

PubMed Abstract | Publisher Full Text | Free Full Tex

16. Gebetsberger J, Polacek N: Slicing tRNAs to boost functional ncRNA diversity RNA Biol. 2013; 10(12): 1798-806.

PubMed Abstract | Publisher Full Text | Free Full Text

17. Martens-Uzunova ES, Olvedy M, Jenster G: Beyond microRNA--novel RNAs derived from small non-coding RNA and their implication in cancer. Cancer Lett. 2013; 340(2): 201-11.

PubMed Abstract | Publisher Full Text

18. Sobala A, Hutvagner G: Transfer RNA-derived fragments: origins, processing, and functions. Wiley Interdiscip Rev RNA. 2011; 2(6): 853-62.

PubMed Abstract | Publisher Full Text

19. Miyoshi K, Miyoshi T, Siomi H: Many ways to generate microRNA-like small RNAs: non-canonical pathways for microRNA production. Mol Genet Genomics. 2010; 284(2): 95-103.

PubMed Abstract | Publisher Full Text

20. Abe M, Naqvi A, Hendriks GJ, et al.: Impact of age-associated increase in 2'-Omethylation of miRNAs on aging and neurodegeneration in Drosophila. Genes Dev. 2014; 28(1): 44-57.

PubMed Abstract | Publisher Full Text | Free Full Text

21. Kumar P, Anaya J, Mudunuri SB, et al:: Meta-analysis of tRNA derived RNA fragments reveals that they are evolutionarily conserved and associate with AGO proteins to recognize specific RNA targets. BMC Biol. 2014; 12(1): 78 . PubMed Abstract | Publisher Full Text | Free Full Text

22. Wang $Q$, Lee I, Ren J, et al:: Identification and functional characterization of tRNA-derived RNA fragments (tRFs) in respiratory syncytial virus infection. Mol Ther. 2013; 21(2): 368-79.

PubMed Abstract | Publisher Full Text | Free Full Text

23. Karaiskos S, Naqvi AS, Swanson KE, et al:: Age-driven modulation of tRNA derived fragments in Drosophila and their potential targets. Biol Direct. 2015; 10(1): 51 .

PubMed Abstract | Publisher Full Text | Free Full Text

24. Kato $\mathrm{M}$, Chen $\mathrm{X}$, Inukai $\mathrm{S}$, et al:: Age-associated changes in expression of small, noncoding RNAs, including microRNAs, in C. elegans. RNA. 2011; 17(10): 1804-20.

PubMed Abstract | Publisher Full Text | Free Full Text

25. Kirkwood TB: A systematic look at an old problem. Nature. 2008; 451(7179): $644-647$.

PubMed Abstract | Publisher Full Text

26. Yin $\mathrm{L}$, Sun $\mathrm{Y}, \mathrm{Wu} \mathrm{J}$, et al:: Discovering novel microRNAs and age-related nonlinear changes in rat brains using deep sequencing. Neurobiol Aging. 2015; 36(2): 1037-1044

PubMed Abstract | Publisher Full Tex
27. Wood $\mathrm{SH}$, Craig T, Li Y, et al.: Whole transcriptome sequencing of the aging rat brain reveals dynamic RNA changes in the dark matter of the genome. Age (Dordr). 2013; 35(3): 763-776.

PubMed Abstract | Publisher Full Text | Free Full Text

28. Mi H, Muruganujan A, Casagrande JT, et al.: Large-scale gene function analysis with the PANTHER classification system. Nat Protoc. 2013; 8(8): 1551-1566. PubMed Abstract | Publisher Full Text

29. Maute RL, Schneider $C$, Sumazin $P$, et al: tRNA-derived microRNA modulates proliferation and the DNA damage response and is down-regulated in $B$ cell lymphoma. Proc Natl Acad Sci U S A. 2013; 110(4): 1404-9. PubMed Abstract | Publisher Full Text | Free Full Text

30. Babiarz JE, Ruby JG, Wang $Y$, et al: Mouse ES cells express endogenous shRNAs, siRNAs, and other Microprocessor-independent, Dicer-dependent small RNAs. Genes Dev. 2008; 22(20): 2773-85. PubMed Abstract | Publisher Full Text | Free Full Text

31. Bühler M, Spies N, Bartel DP, et al:: TRAMP-mediated RNA surveillance prevents spurious entry of RNAs into the Schizosaccharomyces pombe siRNA pathway. Nat Struct Mol Biol. 2008; 15(10): 1015-1023. PubMed Abstract | Publisher Full Text | Free Full Text

32. Hsieh LC, Lin SI, Shih AC, et al.: Uncovering small RNA-mediated responses to phosphate deficiency in Arabidopsis by deep sequencing. Plant Physiol. 2009; 151(4): 2120-2132.

PubMed Abstract | Publisher Full Text | Free Full Text

33. Kawaji $\mathrm{H}$, Nakamura M, Takahashi $\mathrm{Y}$, et al:: Hidden layers of human small RNAs. BMC Genomics. 2008; 9(1): 157.

PubMed Abstract | Publisher Full Text | Free Full Text

34. Lewis BP, Shih IH, Jones-Rhoades MW, et al:: Prediction of mammalian microRNA targets. Cell. 2003; 115(7): 787-98.

PubMed Abstract | Publisher Full Tex

35. Grimson A, Farh KK, Johnston WK, et al.: MicroRNA targeting specificity in mammals: determinants beyond seed pairing. Mol Cell. 2007; 27(1): 91-105 PubMed Abstract | Publisher Full Text | Free Full Text

36. Nielsen JA, Lau P, Maric D, et al.: Integrating microRNA and mRNA expression profiles of neuronal progenitors to identify regulatory networks underlying the onset of cortical neurogenesis. BMC Neurosci. 2009; 10: 98. PubMed Abstract | Publisher Full Text | Free Full Text

37. Valen $E$, Preker $P$, Andersen $P R$, et al:: Biogenic mechanisms and utilization of small RNAs derived from human protein-coding genes. Nat Struct Mol Biol. 2011; 18(9): 1075-1082.

PubMed Abstract | Publisher Full Text

38. Huang V, Li LC: Demystifying the nuclear function of Argonaute proteins. RNA Biol. 2014; 11(1): 18-24.

PubMed Abstract | Publisher Full Text | Free Full Text

39. Schraivogel D, Meister G: Import routes and nuclear functions of Argonaute and other small RNA-silencing proteins. Trends Biochem Sci. 2014; 39(9): 420-431. PubMed Abstract | Publisher Full Text

40. Bartel DP: MicroRNAs: target recognition and regulatory functions. Cell. 2009 136(2): 215-233

PubMed Abstract | Publisher Full Text | Free Full Text

41. Shin C, Nam JW, Farh KK, et al.: Expanding the microRNA targeting code: functional sites with centered pairing. Mol Cell. 2010; 38(6): 789-802. PubMed Abstract | Publisher Full Text | Free Full Text

42. Helwak A, Kudla G, Dudnakova T, et al:: Mapping the human miRNA interactome by CLASH reveals frequent noncanonical binding. Cell. 2013; 153(3): 654-665. PubMed Abstract | Publisher Full Text | Free Full Text

43. Goodarzi H, Liu X, Nguyen HC, et al:: Endogenous tRNA-Derived Fragments Suppress Breast Cancer Progression via YBX1 Displacement. Cell. 2015; 161(4): 790-802.

PubMed Abstract | Publisher Full Text | Free Full Text

44. Haroutunian V, Katsel P, Dracheva S, et al:: The human homolog of the QKI gene affected in the severe dysmyelination "quaking" mouse phenotype: downregulated in multiple brain regions in schizophrenia. Am J Psychiatry. 2006; 163(10): 1834-7.

PubMed Abstract | Publisher Full Tex

45. Wetzel-Smith MK, Hunkapiller J, Bhangale TR, et al:: A rare mutation in UNC5C predisposes to late-onset Alzheimer's disease and increases neuronal cell death. Nat Med. 2014; 20(12): 1452-1457.

PubMed Abstract | Publisher Full Text | Free Full Tex

46. Redies C: Cadherins in the central nervous system. Prog Neurobiol. 2000; 61(6): 11-648.

PubMed Abstract | Publisher Full Text

47. Ford-Perriss $\mathrm{M}, \mathrm{Abud} \mathrm{H}$, Murphy M: Fibroblast growth factors in the developing central nervous system. Clin Exp Pharmacol Physiol. 2001; 28(7): 493-503. PubMed Abstract | Publisher Full Text

48. Lim LP, Lau NC, Garrett-Engele P, et al:: Microarray analysis shows that some microRNAs downregulate large numbers of target mRNAs. Nature. 2005 433(7027): 769-773.

PubMed Abstract | Publisher Full Text

49. Karaiskos S: Dynamics of tRNA Fragments and Their Targets in Aging Mammalian Brain. Open Science Framework. 2016. Data Source 


\section{Open Peer Review}

\section{Current Peer Review Status:}

\section{Version 1}

Reviewer Report 03 January 2017

https://doi.org/10.5256/f1000research.10897.r18880

(c) 2017 Kamenetzky L et al. This is an open access peer review report distributed under the terms of the Creative Commons Attribution License, which permits unrestricted use, distribution, and reproduction in any medium, provided the original work is properly cited.

\section{Laura Kamenetzky}

Institute of Medical Microbiology and Parasitology (IMPaM), Faculty of Medicine, University of Buenos Aires (UBA) and National Scientific and Technical Research Council (CONICET), Buenos Aires, Argentina

\section{Natalia Macchiaroli}

Institute of Medical Microbiology and Parasitology (IMPaM), Faculty of Medicine, University of Buenos Aires (UBA) and National Scientific and Technical Research Council (CONICET), Buenos Aires, Argentina

The manuscript adds important and relevant work on tRFs present in rat brains at three different time points. The methodology is well-written and able to be replicated. The results demonstrate that tRFs abundance is dynamically regulated in the context of age and that tRFs contain 7-mers which match 3' UTR regions of relevant mRNAs. Also, the tRFs analysis have an added value revealing unannotated tRNA genes for multiple species.

There are minor issues (indicated below):

It would be interesting to add more detail of the criteria used to determine the expression level of the miRNAs that are compared with the tRFs. It may also be explained in more detailed how the authors selected the 5 miRNAs for comparisons.

It would be interesting to show a table with the number of tRFs sites (single or multiple) per mRNA target since in the supplementary material it is difficult to see. Also targets regulated by distinct tRFs.

The legend of Figure 4 mentions the yellow color that is absent in the figure.

Competing Interests: No competing interests were disclosed.

We confirm that we have read this submission and believe that we have an appropriate level of expertise to confirm that it is of an acceptable scientific standard. 
Reviewer Report 16 December 2016

https://doi.org/10.5256/f1000research.10897.r17976

(C) 2016 Tatarinova T. This is an open access peer review report distributed under the terms of the Creative Commons Attribution License, which permits unrestricted use, distribution, and reproduction in any medium, provided the original work is properly cited.

\section{Tatiana V. Tatarinova}

Center for Personalized Medicine (CPM), Spatial Sciences Institute, Children's Hospital Los Angeles, University of Southern California, Los Angeles, CA, USA

The paper is well-written with appropriate title and adequate abstract. There are, however, several minor comments.

1. The authors mention in passing the results of Helwak et al. Would it be possible to validate the predicted seed regions using the data from the CLASH experiments?

2. The results appear to agree with their previous work in Drosophila, with the difference that Ago IP was used in the flies. This difference is not discussed in sufficient detail here and needs to be further elaborated.

3. Have the authors considered a "target" of the tRNA itself, from which a fragment is produced? After all, there is base complementarity in the stem for both 5' and 3' tRFs.

4. A recent paper in Science ${ }^{1}$ implicated possible tRF matches in promoter regions. Have the authors considered these targets?

\section{References}

1. Chen Q, Yan M, Cao Z, Li X, et al.: Sperm tsRNAs contribute to intergenerational inheritance of an acquired metabolic disorder.Science. 2016; 351 (6271): 397-400 PubMed Abstract | Publisher Full Text

Competing Interests: No competing interests were disclosed.

I confirm that I have read this submission and believe that I have an appropriate level of expertise to confirm that it is of an acceptable scientific standard. 
The benefits of publishing with F1000Research:

- Your article is published within days, with no editorial bias

- You can publish traditional articles, null/negative results, case reports, data notes and more

- The peer review process is transparent and collaborative

- Your article is indexed in PubMed after passing peer review

- Dedicated customer support at every stage

For pre-submission enquiries, contact research@f1000.com 